\title{
The evolution of a tooth brush: from antiquity to present- a mini-review
}

\begin{abstract}
Tooth brush has been an integral part of a daily routine across many cultures around the world from the times of antiquity to the 21 st century. A variety of cultures across the world have used many different materials from certain tree twigs like "Neem and "Miswak" to bird feathers and pig hair. While the essential function of the tooth brush which was to mechanically cleanse the mouth has remained the same over the ages, the 21 st century is looking to embrace technology to redefine what the "tooth brush" can do. In this mini review we present a historical background of the toothbrush and how it has evolved over the years and what are the future possibilities that can help understand people's brushing habits that can be used to develop public health programs.
\end{abstract}

Keywords: tooth brush, neem, miswak, blue tooth, data collection
Volume 2 Issue 4 - 2015

\author{
Aditya Tadinada,' Jessica Kilham,' Pooja \\ Bysani,' Aadarsh Gopalakrishna' \\ 'Department of Oral and Maxillofacial Radiology, UCONN \\ School of Dental Medicine, USA \\ ${ }^{2}$ Department of Public services health sciences librarian, \\ Quinnipiac University, USA \\ ${ }^{3}$ Department of General Dentistry, UCONN School of Dental \\ Medicine, USA \\ ${ }^{4}$ Department of Reconstructive Sciences, UCONN School of \\ Dental Medicine, USA
}

\begin{abstract}
Correspondence: Aditya Tadinada, Assistant Professor, Department of Oral and Maxillofacial Radiology, UCONN School of Dental Medicine, 263, Farmington Avenue, Farmington, CT, 06032, USA,Tel 860679 7057, Email tadinada@uchc.edu
\end{abstract}

Received: May 27, 2015 | Published: June 15, 2015

\section{Introduction}

Tooth brushing is an essential part of an oral hygiene routine. This routine typically includes the use of a tooth brush and a tooth paste. The current day tooth brush consists of a head of tightly clustered bristles mounted on a handle, which facilitates the cleansing of both accessible and hard-to-reach areas in the mouth. The history of tooth brushing is a long and interesting saga that has undergone many iterations of a similar conceptual design with a variety of materials. While modern tooth brushes are embracing the latest technological advances and gleaning information ranging from stroke pressure to oral hygiene habits, the early beginnings were very different. In this mini-review, the historical beginnings of a tooth brush to the most modern advances and technological integration associated with tooth brushing are presented.

\section{Discussion}

A variety of oral hygiene measures have been used since before recorded history prior to the toothbrush, ${ }^{1}$ excavations have unearthed chew, tree twigs, bird feathers, animal bones and porcupine quills that are believed to be used as a tool for oral hygiene. In a variety of cultures around the world, the tooth brush has been found in various forms essentially doing the same function. ${ }^{2}$ Although it would be challenging to track the origins through centuries with year specific chronological certainty, there is evidence from ancient texts that shed light on this often under recognized tool. Tools specifically made for tooth brushing date back to $3500-3000 \mathrm{BC}^{2}$ These primitive tooth brushing tools, made a brush by fraying the end of a twig, date back to ancient Babylonia and Egypt. ${ }^{2}$ Tombs of the ancient Egyptians have been found containing tooth-sticks. Records start to emerge from modern day China about the use of "chewing sticks" around 1600BC. "Chewing sticks" addressed another aspect of oral carefresh breath and were made from aromatic tree twigs. ${ }^{3}$ Additional evidence from ancient China indicates that hair from the necks of pigs was used to form bristles in early toothbrushes. Neem twigs were used as a toothbrush in ancient India. ${ }^{4}$ Rather than brushing the teeth, the edge of the twig was chewed to form bristles that cleaned the teeth. The practice of oral hygiene included chewing on the twig until it developed bristles and then it was used to brush the teeth. ${ }^{4}$ Along with the forming of bristles through chewing, the twig has medicinal qualities that are effective for the prevention of caries and plaque from forming on the teeth. ${ }^{5}$ Supported by evidence in current literature, the use of Neem twigs for oral hygiene are in fact beneficial. ${ }^{6}$ The trifecta of anti-plaque, anti-cavity and antibacterial qualities of Neem make it desirable and advantageous for developing countries to recommend the use of these sticks as a medium to improve dental and oral health of its people. ${ }^{5}$

Neem is a tree belonging to the mahogany family. It grows in tropical and semi-tropical regions and is found in India, Myanmar, Bangladesh, Sri Lanka, Pakistan, and parts of Iran. The tree has been revered as the "village pharmacy" and has been acknowledged to have a variety of versatile resources in Ayurvedic medicine. ${ }^{7}$ People from that geographic area genuinely believe in its many healing properties and its power to fight physical illness. For example, the tree bark is used for treating gum diseases, oils are used for treating dermatological conditions, flowers to control phlegm, fruit from the tree was used to treat stomach ailments and the roots used to make astringent. ${ }^{7}$ Neem, in its full bloom, can aid in healing by keeping the area clean and disinfected. In the Middle Eastern cultures, the use of an aromatic twig called miswak is referenced in the literature as a natural 
toothbrush. ${ }^{5,8}$ Similarly to Neem, a twig from the Salvadoraceae family of plants was chewed on until the end became frayed into a brush. The brush-end is used to clean the teeth. The beneficial effects of Miswak in respect of oral hygiene and dental health are partly due to its mechanical action and partly due to pharmacological actions. Moreover, the use miswak for oral hygiene is referenced in Muslim hygienic jurisprudence. ${ }^{9}$ (Figure 1,2).

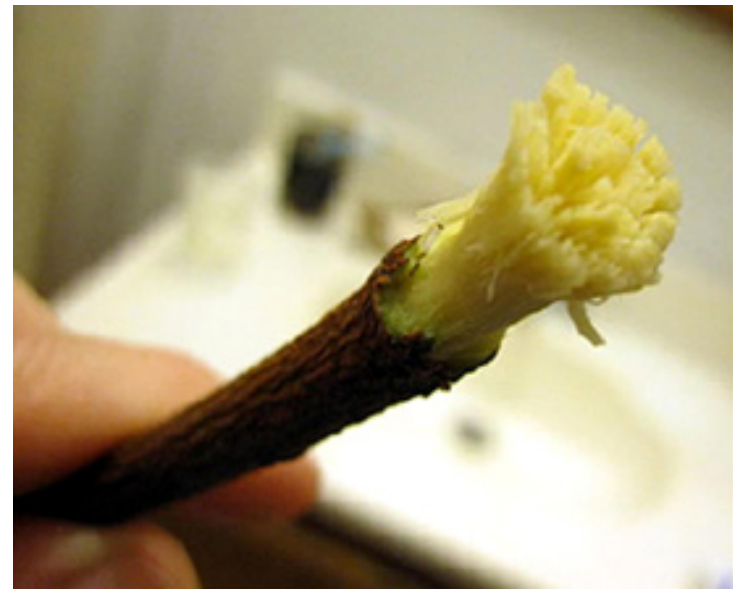

Figure I Neem stick.

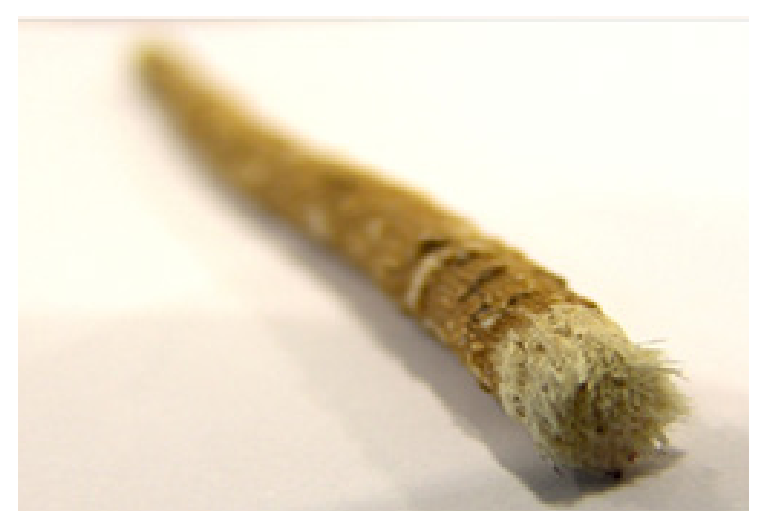

Figure 2 Miswak.

Bristled toothbrushes did not find their place in Europe until the 1600 's. ${ }^{10}$ The 17 th and 18 th centuries had dentists in France promoting the use of toothbrushes and slightly later in England. The first written reference to a toothbrush in the English language dates back to 1651 when it was written about in the Memoirs of the Verney Family during the English Civil War. ${ }^{11}$ In this reference, it was noted that it was a gift of the new Paris luxury-'the Teeth Brushes and boxes. ${ }^{11}$ As the Industrial Revolution took hold in Europe the stage was set for manufacturing and consumer goods. ${ }^{3}$ William Addis ${ }^{12}$ is credited with designing the first mass-produced toothbrush in England, which entered the market in 1780. On the other side of the Atlantic, the first American to patent a toothbrush was Wadsworth HN. ${ }^{10,12}$ By 1885 , American companies began the mass-production of toothbrushes although a large scale consumer market had not yet been established. ${ }^{10}$ The Prophylactic-tic toothbrush made by the Florence Manufacturing Company is one example of an early American-made toothbrush and was the first to sell individually packaged toothbrushes. While toothbrushes in the United States were mass produced by the 1900's, the increased consumer demand was not noted until after the return of American soldiers from World War I. The widespread adoption of European standards of oral hygiene by American soldiers was brought home. Throughout the twentieth century, traditional toothbrushes took on incremental advancement (Figure 3).

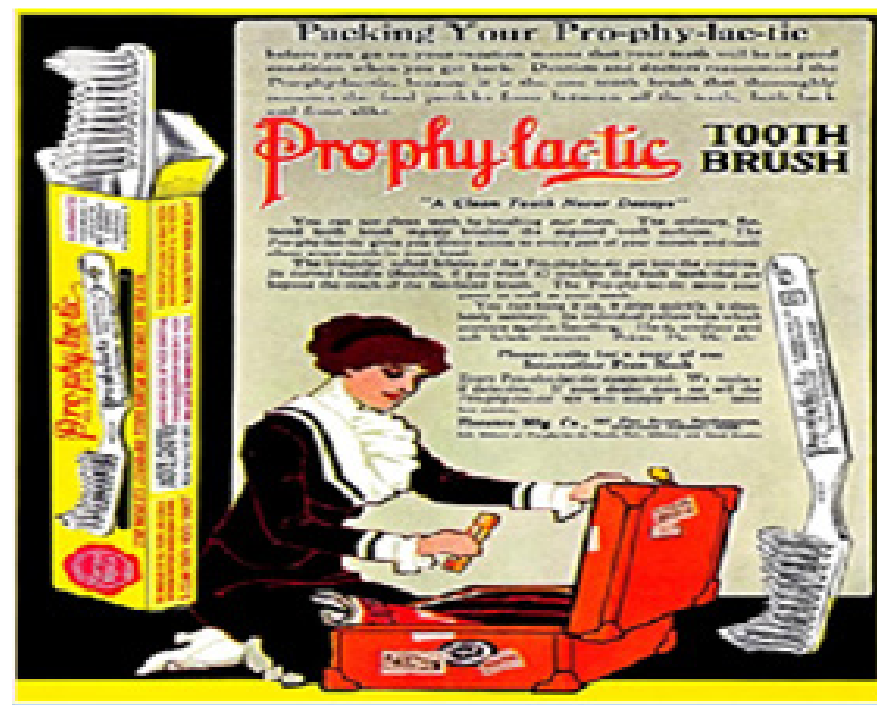

Figure 3 Prophylactic Tooth brush. Pro-phy-lac-tic Brush Co. Wall Street Journal, September 3, 1924:3.

By 1938, nylon bristles were introduced in toothbrushes manufactured by DuPont. ${ }^{12}$ Prior to this, animal hair and other organic materials had been used to create the bristles. The change of bristle material contributed to the decrease of bacteria on the actual brush. The prototype of the first electric toothbrush was developed in Switzerland by Dr. Phillippe- Guy Woog in 1939, but it wasn't released until 1954. In 1960, Squibb marketed the first Americanmade electric toothbrush called the Broxodent. ${ }^{12}$ General Electric introduced a rechargeable cordless toothbrush in 1961, and in 1987, Interplak was the first rotary-action electric toothbrush for home use. ${ }^{12}$ Today, both manual and electric toothbrushes come in many shapes and sizes and are typically made of plastic molded handles and nylon bristles. The most recent toothbrush models include handles that are straight, angled, curved, and contoured with grips and soft rubber areas to make them easier to hold and use. Toothbrush bristles are usually synthetic and range from very soft too soft in texture, although harder bristle versions are available. Toothbrush heads range from very small for young children to larger sizes for older children and adults and come in a variety of shapes such as rectangular, oblong, oval and almost round.

Powered brushes have continued to evolve with numerous models that either rotate (fully or partially) or vibrate (sonic or ultrasonic), or a combination of the two. Oral-B and Philips Sonicare are probably the most visible in the current marketplace, with variations and features from UV sterilization of the heads to USB recharging. There are now new models that are Bluetooth enabled and can record a person's brushing time and technique even. In 1987, David Giuliani, an electrical engineer, met with University of Washington professors Drs. David Engel and Roy Martin. They formed a new company named GEMTech to promote a dental hygiene device using a piezoelectric multi-morph transducer. After several years of research 
and creating prototypes, the Sonicare toothbrush was introduced in November 1992 at a periodontal convention in Florida. In 1995, GEMTech changed its name to Optiva Corporation. In October 2000, Philips Domestic Appliances and Personal Care, a division of Philips, acquired Optiva Corporation. A few months later Optiva Corporation changed its name to Philips Oral Healthcare, Inc. By the end of 2001, Sonicare had become the top selling rechargeable power toothbrush in the United States. ${ }^{8}$ In 2003, to improve Philips brand recognition in the US, Philips began rebranding the Sonicare toothbrush as "Philips Sonicare". The brush head vibrates at hundreds of times per second, with the latest models at 31,000 strokes per minute. Rather than connecting to its charger with conductors, it utilizes inductive charging-the charger includes the primary winding of the voltagereducing transformer and the fat handle of the brush includes the secondary winding. The replaceable head is also driven magnetically (Figure $4 \& 5$ ).
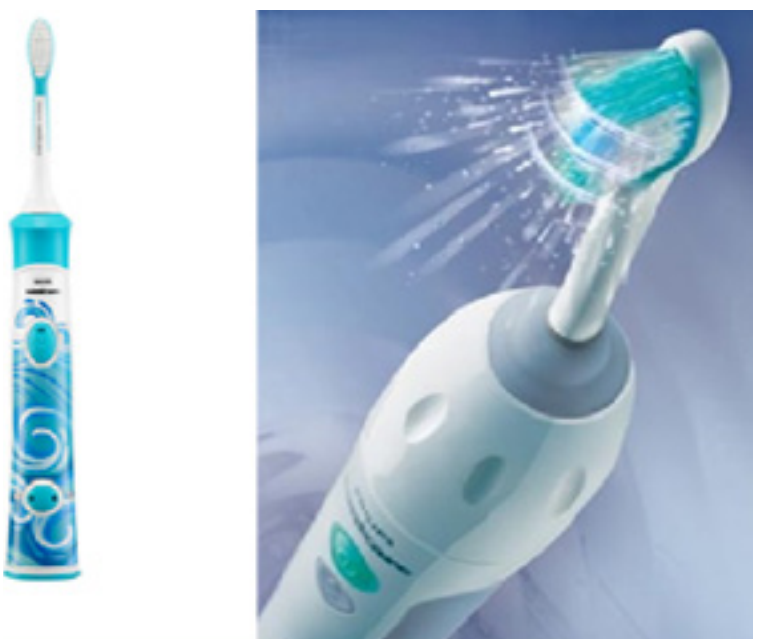

Figure 4 Soni care tooth brush.

Image source: Phillips.com/c-cs/oral-healthcare.html

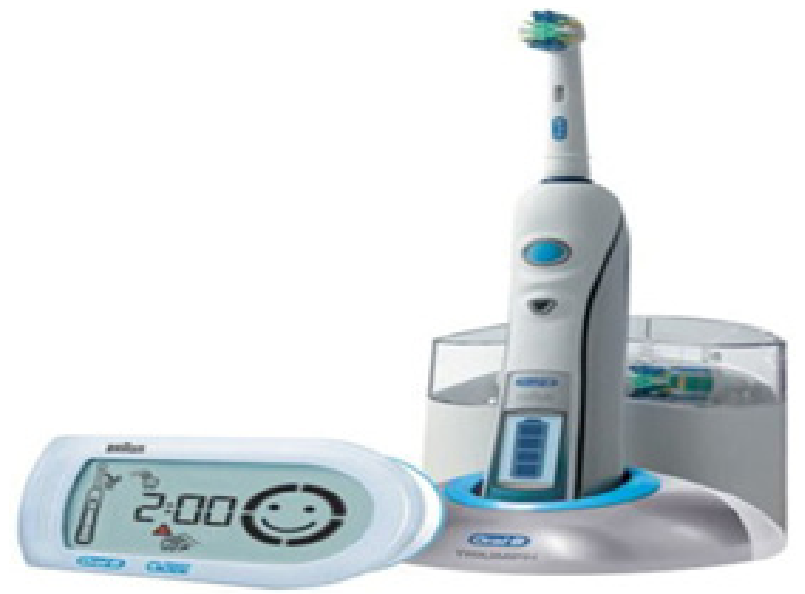

Figure 5 Oral B tooth brush with blue tooth technology.

Image source: www.oralb.com

Toothbrushes have come a long way in the past 100 years. ${ }^{3}$ Next generation toothbrushes are being designed to include an interactive experience and follow characteristics of the Information age. Data about personal brushing experience is collected and can be used to make focused decisions related to oral hygiene. ${ }^{13}$
Bluetooth Smart technology is being used to replace cables that connect multiple devices. The implications of this technology can be seen in connection data collected on tooth brushing habits to mobile phones. Built-in sensors can now track and record daily brushing habits offering users insight into personal oral hygiene practices available at their fingertips. It also answers the age old questions from parents regarding if their children brushed their teeth. New motion techniques are now being seen in newer toothbrushes- things such as vibrating technology is added to make tooth brushing more efficient. Many modern toothbrushes are programmable sousers can enable their smartphone as a "remote control" to customize personal brushing needs, including setting target session length and selecting are preferred modes. Parents can set recommended personalized programs for themselves and the kids based on their specific needs. The modern tooth brush offers many exciting options for kids to encourage them to brush better. A new smart brush "Kolibree" offers patented blue tooth connectivity with built in games to excite children and has a point system to encourage kids and adults to brush the right way and keep them on track with the recommended brushing schedule. Their brush also has a motion sensor technology for efficient brushing. Perhaps the integration of this connectivity will offer us new insights into people's brushing habits and serve as a major public health intervention tool (Figure 6).
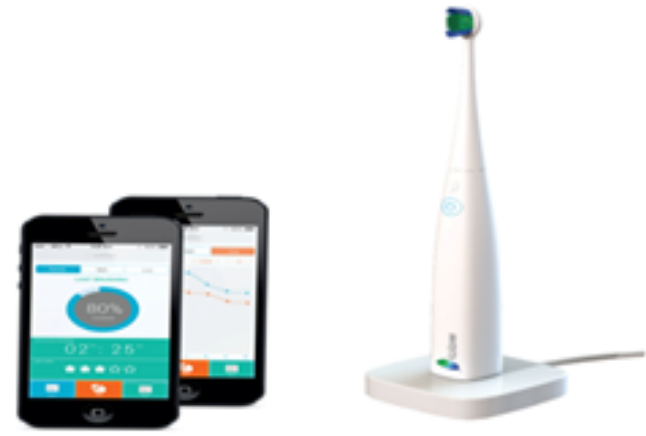

Figure 6 Kolibree smart tooth brush with blue tooth technology. Image source: Kolibree.com

The basic fundamentals of tooth brushing have not changed since the times of the Egyptians and Babylonians - a handle to grip, and a bristle-like feature with which to clean the teeth. But the 21 st century will overhaul the traditional function of a tooth brush by making it "smarter". The development of Nano-technology and miniaturization of electronics and the ability to store data in discretely small and water proof areas and its ability to be integrated into tooth brushes will forever change the paradigm of our perception about tooth brushing. There are a variety of interesting possibilities that can be developed with this integration.

\section{Conclusion}

Based on this mini-review, it appears that over its long history, the toothbrush has evolved continuously through the centuries but the 21st century is all set to take the tooth brush to a new zenith by integration of technology that will benefit the end user. The ability to gather data dynamically and analyze it can help in understanding people's bushing habits and can aid in developing focused brushing programs based on patient specific needs and can eventually help in developing large scale public health programs. 


\section{Acknowledgments}

None

\section{Conflicts of interest}

The author declares that there are no conflicts of interest.

\section{Funding}

None.

\section{References}

1. Samons R. Control of dental plaque. In: Medical biofilms detection prevention and control. Chichester, USA: John Wiley \& Sons; 2003, 223 p.

2. Zhou ZR, Yu HY, Zheng J, et al. Dental biotribology. New York, USA: Springer: 2013;18.

3. Fischman SL. The history of oral hygiene products: how far have we come in 6000 years? Periodontol. 2000;15:7-14.

4. Kumar JV. Oral hygiene aids. In: Hiremath SS(editor). Textbook of preventive and community dentistry. $2^{\text {nd }}$ ed. India: Elsevier. 2011. $412 \mathrm{p}$.

5. Elangovan A, Muranga J, Joseph E. Comparative evaluation of the antimicrobial efficacy of four chewing sticks commonly used in south india: An in vitro study. Indian J Dent Res. 2012;23(6):840.
6. Sharma A, Sankhla B, Parkar SM, et al. Effect of traditionally used neem and babool chewing stick (datun) on streptococcus mutans: An invitro study. J Clin Diagn Res. 2014;8(7):ZC15-ZC17.

7. Kumar VS, Navaratnam V. Neem (Azadirachta indica): prehistory to contemporary medicinal uses to humankind. Asian Pac J Trop Biomed. 2013;3(7):505-514.

8. Naseem S, Hashmi K, Fasih F, et al. In vitro evaluation of antimicrobial effect of miswak against common oral pathogens. Pak J Med Sci. 2014;30(2):398-403.

9. Laird LD, Barnes LL, Hunter-Adams J, et al. Looking islam in the teeth: The social life of a somali toothbrush. Med Anthropol Q. 2015.

10. Jardim JJ, Alves LS, Maltz M. The history and global market of oral home-care products. Braz Oral Res. 2009;23(1):17-22.

11. Tooth-brush. In OED online. Oxford University Press.

12. William Addis, Wadsworth HN, DuPont. Library of Congress. Who invented the toothbrush and when was it invented? Everyday Mysteries. 1938.

13. Walji MF, Coker O, Valenza JA, et al. A persuasive toothbrush to enhance oral hygiene adherence. AMIA Annu Symp Proc. 2008;6:1167. 